\title{
Acceptance of Wearable Technology: A Meta-Analysis
}

\author{
Chenming Peng \\ University of Chinese \\ Academy of Sciences \\ pengchenming14@mails. \\ ucas.ac.cn
}

\author{
Nannan Xi \\ University of Vaasa \& \\ Tampere University \\ nannan.xi@tuni.fi
}

\author{
Hong Zhao \\ University of Chinese \\ Academy of Sciences \\ zhaohong@ucas.ac.cn
}

\author{
Juho Hamari \\ Gamification Group \\ Tampere University \\ juho.hamari@tuni.fi
}

\begin{abstract}
Knowing what factors drive wearable technology adoption can help companies succeed in the competitive market of wearables. In this study, we conduct a meta-analysis on the relationships of technology acceptance of wearable technology based on the extant corpus (142 effect sizes from 44 samples collected in 11 countries). The results confirm the basic expectation that the core constructs of technology acceptance models as well as reveal that perceived enjoyment and usefulness are the most important to the adoption of wearables. However, more interestingly, a granular analysis of moderating effects shows that cultural factors including uncertainty avoidance, future orientation and humane orientation can significantly moderate the relationships between different determinants and wearable adoption. In addition, compared with other types of smart wearables, the users of smartwatches would place more weight on perceived selfexpressiveness. These findings offer insights for future wearables-related research and also have practical implications for designing and developing successful wearable products.
\end{abstract}

\section{Introduction}

Wearable technology refers to a category of smart electronic devices that can be worn by the users and often includes detecting, tracking and analyzing information regarding biological and physiological data. It can be seen there has been a growing trend in the market of consumer-grade wearables during the past ten years, especially in the entertainment (e.g. gaming wearables, see [4]) and health sector (see [49]). Based on the forecast of Gartner, the end-user spending on wearables will total $\$ 81.5$ billion in 2021 , an $18.1 \%$ increase from $\$ 69$ billion in 2020. The increasingly fierce market competition highlights the necessity of understanding the factors that influence consumers' attitude and willingness to purchase and use wearable products. Additionally, the importance of these factors to users may differ across various countries and products.

In literature, the current studies have examined factors such as perceived usefulness, perceived ease of use, performance expectancy, effort expectancy, and hedonic motivation, see e.g., [33][40][50][56][57][60]; subcultural appeal, see e.g., [24][25][26]); selfexpressiveness, see e.g., [11][44]; affective quality, see e.g., [25][26]; and privacy risk, see e.g., [34][44], however, it can be seen that these scattered empirical evidence hardly provide a holistic and comprehensive view on the in-depth mechanism of what kinds of, how and under which conditions these factors differently lead to wearable adoption and acceptance. In addition, in terms of the research methodology, the generalized assessment of the relative importance of diverse key factors to wearable adoption is still unknown, given the majority of prior studies have investigated the effectiveness of these factors with one or two small samples for a particular type of wearable technology in a single country. Further, there seems no consensus on the effects of different factors on the adoption of wearables. To be more specific, for example, [15] found that the effect of perceived ease of use on adoption intention was not significant, while most studies have proved that perceived ease of use is significantly associated with the adoption intention of wearables. More importantly, there is a lack of discussion on the boundary conditions influencing wearable adoption, such as factors related to cultural factors and wearable product types. Such investigation is essential considering that the wearable technology market spreads across the world and contains various types of wearable devices, such as smartwatches, smart glasses, and wearable healthcare devices. 
Therefore, in this study, we aim at addressing the mentioned research gaps by conducting a meta-analytic review to provide a more concise view of determinants of adoption of wearable technology from the perspective of technology acceptance model (TAM) [13]. Specifically, we first integrate numerous but sporadic findings to develop a comprehensive framework for explaining the relationships between different key factors and wearable adoption. Second, the importance of factors in wearable adoption are further assessed through a meta-analysis by estimating the mean values and range of these relationships. Third, the meta-analysis accumulates findings from diverse research objects and various countries and areas; thus, we further investigate the moderating effects of cultural-related factors and wearable technology type on the above relationships.

\section{Research framework and hypotheses}

In this section, we first hypothesize the relationships between different influencing factors and the adoption of wearables, and then theorize the moderators mainly including cultural-related factors and wearable technology type. Figure 1 below briefly presents the research framework.

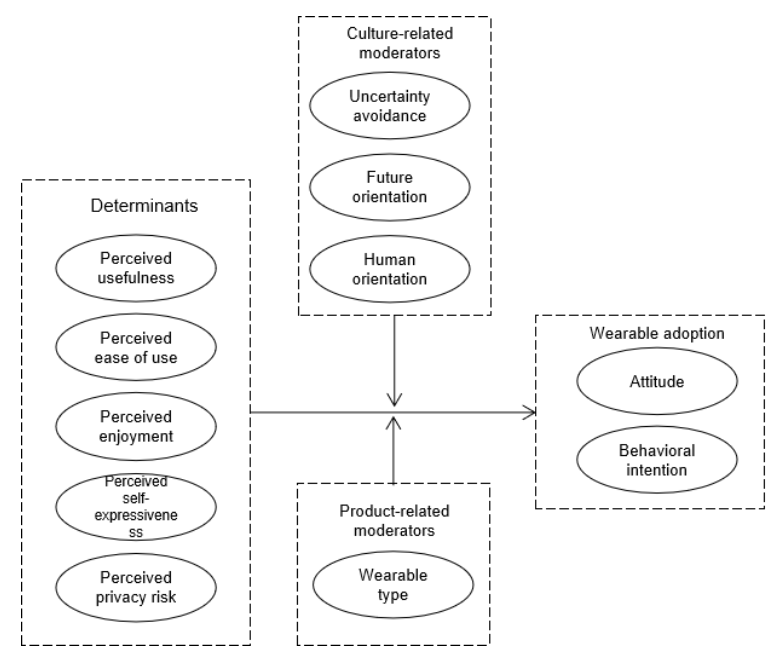

Figure 1. The meta-analytic framework

\subsection{Determinants in wearable adoption}

Perceived usefulness. The perceived usefulness of wearable technology refers to the degree to which the wearable technology is useful to help consumers achieve their goals, such as health improvement. TAM predicts individuals who believe the perceived usefulness of technology tends to display positive responses. UTAUT2 (the unified theory of acceptance and use of technology) also argues that performance expectancy (an alias name for usefulness, defined as the degree to which the technology is effective to users in performing specific activities) can determine individuals' behavioral intentions. In addition, the recent studies also empirically demonstrate that usefulness can enhance individuals' willingness to purchase and use wearable technology (e.g., [12][33]). Thus,

H1: Perceived usefulness has a positive impact on the adoption of wearables.

Perceived ease of use. The perceived ease of use of wearable technology, in this study, refers to the degree to which using the wearable technology would be free of effort. Perceived ease of use emphasizes the ergonomics of a product [23]. This construct also originates from TAM and has an alternative name, called effort expectancy, in UTAUT2. It can be assumed that when customers perceive high ease of using a certain wearable technology, they would be more likely to conduct actual use. The literature in wearable technology adoption also suggests a direct positive effect of perceived ease of use on usage intention and behavior (e.g., [26][33][65]). Thus,

H2: Perceived ease of use has a positive impact on the adoption of wearables.

Perceived enjoyment. Following the literature in technology adoption [61], perceived enjoyment is defined as the delight or enjoyment derived from adopting and utilizing wearable technology. Perceived enjoyment reflects the hedonism of a product [39]. When technology-specific enjoyment increases, usage intention would also become higher. In the context of wearable technology, studies reveal that users pay attention to the perceived enjoyment of smart wearable products [43][66]. Thus,

H3: Perceived enjoyment has a positive impact on the adoption of wearables.

Perceived self-expressiveness. Perceived selfexpressiveness describes the degree to which a technology can reflect one's personal characteristics [36]. The wearable that is worn by users can also be seen and observed by others; thus is able to influence others' impression of the user. In this case, users consider wearable technology not only as an IT product but also as a fashion product [11]. Recent studies show evidence that users indeed attach importance to perceived self-expressiveness and intend to use wearable technology to express their own uniqueness (e.g., [11][24][26]). Thus,

H4: Perceived self-expressiveness has a positive impact on the adoption of wearables.

Perceived privacy risk. In line with prior studies [17], perceived privacy risk represents the risk of wearable technology misusing consumers' personal 
information. Wearable technology can collect huge amounts of personal information and data of the users. Moreover, these smart wearable devices can easily track and monitor users' real-time positions via an embedded GPS feature. These sensitive information bring anxiety and concerns to users such that perceived privacy risk would inhibit their adoption willingness of wearable technology [34][51]. Thus,

H5: Perceived privacy risk has a negative impact on the adoption of wearables.

\subsection{Moderators for wearable adoption}

Uncertainty avoidance. Uncertainty avoidance pertains to the extent to which individuals alleviate the unpredictability of future events [20]. Individuals in high-uncertainty avoidance cultures are more riskaverse [54]. Therefore, compared with low-uncertainty avoidance cultures, the factor that leads to perceived risk should have a higher negative impact on usage intention in high-uncertainty avoidance cultures. Given perceived privacy risk naturally deteriorates perceived risk, the negative effect of perceived privacy risk on usage intention should be higher in high-uncertainty avoidance cultures. In addition, the most important factor consumers usually consider first when making the purchase decision is functionality [8]. [39] found that only when functionality is explicitly introduced to consumers, would they feel safer. This finding reveals that functionality can reduce perceived risk. Because perceived usefulness is highly related to the functionality of wearable technology, perceived usefulness is expected to be associated with risk and become more important in high-uncertainty avoidance cultures. This expectation is consistent with the observation in [68] that the interaction between uncertainty avoidance and perceived usefulness would have a significantly positive effect on consumer acceptance of e-commerce. Thus,

H6: The positive influence of perceived usefulness on the adoption of wearables is relatively stronger in a high-uncertainty avoidance culture than in a lowuncertainty avoidance culture.

H7: The negative influence of perceived privacy risk on the adoption of wearables is relatively stronger in a high-uncertainty avoidance culture than in a lowuncertainty avoidance culture.

Future orientation. Future orientation refers to the extent to which individuals engage in future-oriented behaviors, such as planning, investing in the future, and delaying gratification [20]. In a high-future orientation culture, individuals care about the consequences of their actions and are self-responsible and super-achievers [30]. The regulatory focus theory [18] indicates that self-responsible consumers usually have prevention goals pertaining to those that ought to be met. In [9], consumers with prevention goals show greater interest in the utilitarian attributes of a product. The utilitarian benefits of wearable technology can be featured as perceived usefulness. Therefore, the future orientation would enhance the impact of perceived usefulness on wearable technology adoption. In contrast, in a low-future orientation culture, consumers possess a hedonistic orientation towards time and life and seek hedonic gratification and enjoyment [70]. Then, the future orientation would restrain the effectiveness of perceived enjoyment on wearable technology adoption. Thus,

H8: The positive influence of perceived usefulness on the adoption of wearables is relatively stronger in a high-future orientation culture than in a low-future orientation culture.

H9: The positive influence of perceived enjoyment on the adoption of wearables is relatively weaker in a high-future orientation culture than in a low-future orientation culture.

Humane orientation. Humane orientation refers to the extent to which a society encourages and rewards individuals for being fair, altruistic, generous, caring, and kind to others [20]. In the high-humane orientation culture, individuals show great concerns about the well-being of people [14]. The ergonomics of the technology determines the well-being of using technology. According to product design theory [23], perceived ease of use reflects the ergonomics of a technology. It can be assumed that humane orientation would strengthen the effect of perceived ease of use on wearable technology adoption. Moreover, studies have shown a high-humane orientation working environment can help leaders to foster a sense of trust in the followers [64], implying that humane orientation enhances trust. In a trustworthy environment, individuals might pay less attention to privacy risk, since they believe firms of wearables would not misuse their personal information. Thus, humane orientation could further diminish the negative effect of perceived privacy risk on the adoption of wearables. Thus,

H10: The positive influence of perceived ease of use on the adoption of wearables is relatively stronger in a high-humane orientation culture than in a lowhumane orientation culture.

H11: The negative influence of perceived privacy risk on the adoption of wearables is relatively weaker in a high-humane orientation culture than in a lowhumane orientation culture.

Smartwatches vs. other types. Multiple types of smart wearable products have been investigated in prior studies, such as smartwatches [11], smart glasses [17], and wearable healthcare technology [34]. Consumers usually consider watches as fashion 
products with symbolic benefits that help them to express their self-image [53] and obtain social benefits, while having no or a weaker expectation of the majority of other types of wearable devices. Accordingly, the perceived self-expressiveness that reflects symbolic benefits might be more important for smartwatch users. Thus,

H12: Among the wearable products, the positive influence of perceived self-expressiveness is stronger on the adoption of smartwatches than the adoption of other types of wearables.

\section{Database development}

\subsection{Data collection}

We conducted a meta-analytic review on the relationships between five determinants and wearable adoption as well as the moderators among them. Various databases were employed to identify relevant studies in the literature. First, we searched for published articles via checking electronic databases, including EBSCO, ProQuest ABI/INFORM, ScienceDirect, Web of Science, Scopus, Emerald, and JSTOR. Then, we searched for relevant theses in ProQuest Dissertations and Theses. Finally, we identified relevant working papers in SSRN, Google Scholar, ResearchGate, and ACM Digital Library. We used "wearable" together with "acceptance or adoption or intention use or determinant" as the search terms. After the search process, we only kept those identified studies that provided correlations of interest since correlation is the most common effect size in this research stream. Eventually, we identified a total of 40 articles with 44 independent samples and 142 effect sizes, including two working papers. The number of articles included is consistent with several published meta-analyses in marketing, such as [35] (47 articles), [55] (42 articles), and [59] (37 articles). All articles are listed in Table 1.

Table 1. Articles involved in the meta-analysis

\begin{tabular}{|c|c|c|c|c|c|c|c|}
\hline \multicolumn{2}{|c|}{ Study Country/area } & \multicolumn{2}{|c|}{ Sample Wearable type } & \multirow{2}{*}{$\begin{array}{l}\text { Study } \\
{[34]}\end{array}$} & \multirow{2}{*}{$\begin{array}{l}\text { Country/area } \\
\text { United States }\end{array}$} & \multicolumn{2}{|c|}{ Sample Wearable type } \\
\hline [5] & South Korea & 342 & Wearable devices & & & 260 & Wearable healthcare devices \\
\hline [7] & Hong Kong & 171 & Wearable healthcare devices & [37] & United States & 574 & Smartwatch \\
\hline [10] & United States & 120 & Smart vest \& smartwatch & {$[38]$} & Netherlands & 182 & $\begin{array}{l}\text { Smart phone, wristband, \& } \\
\text { watch }\end{array}$ \\
\hline [11] & South Korea & 562 & Smartwatch & [40] & India & 273 & Wearable healthcare devices \\
\hline [12] & Malaysia & 226 & Smartwatch & {$[41]$} & South Korea & 877 & Wearable healthcare devices \\
\hline [15] & China & 232 & Fitness Wearable & [43] & United States & 228 & Smart glasses \\
\hline [15] & China & 230 & Medical wearable & [44] & German & 201 & Smart glasses \\
\hline [16] & United States & 256 & Wearable fitness devices & {$[45]$} & German & 201 & Smart glasses \\
\hline [17] & German & 611 & Smart glasses & [49] & United States & 277 & Wearable healthcare devices \\
\hline [21] & Taiwan & 170 & Smartwatch (users who used) & {$[50]$} & Taiwan & 376 & Smart glasses \\
\hline [21] & Taiwan & 170 & $\begin{array}{l}\text { Smartwatch (users who never } \\
\text { used) }\end{array}$ & {$[51]$} & India & 815 & Wearable healthcare devices \\
\hline [22] & Taiwan & 260 & Smartwatch & {$[56]$} & China & 392 & Wearable fitness devices \\
\hline [24] & South Korea & 1138 & Wearable devices & {$[57]$} & China & 325 & Wearable healthcare devices \\
\hline [26] & South Korea & 363 & Smartwatch & {$[58]$} & $\begin{array}{l}\text { United Arab } \\
\text { Emirates }\end{array}$ & 108 & Wearable devices \\
\hline [25] & South Korea & 200 & Smartwatch & {$[60]$} & Turkey & 707 & Smart t-shirt \& smart bra \\
\hline [27] & South Korea & 247 & Wearable fitness devices & {$[62]$} & China & 158 & Wearable healthcare devices \\
\hline [28] & India & 386 & Smartwatch & [63] & German & 353 & Wearable healthcare devices \\
\hline [29] & German & 2086 & Wearable locating systems & [65] & Taiwan & 212 & Smartwatch \\
\hline [31] & China & 333 & Wearable healthcare devices & {$[66]$} & South Korea & 375 & Wearable devices \\
\hline [32] & China & 146 & Wearable healthcare devices & {$[67]$} & Netherlands & 76 & Smart glasses \\
\hline [33] & United States & 206 & Wearable fitness devices & [69] & China & 436 & Wearable healthcare devices \\
\hline
\end{tabular}

\subsection{Coding process}

We followed the definitions being proposed in section 2 to code variables. If a sample has two effect sizes representing the same relationship, we took the average. Moreover, there are missing values in reliability scores of drivers (7/142) and reliability scores of consumers' responses to wearable technology $(10 / 142)$. These numbers of missing values are far fewer than those in prior meta-analyses, such as 90 missing values out of 123 effects in [6]. As with prior meta-analyses (e.g., [1][6]), we replaced the missing values with mean values. Finally, cultural dimension 
data comes from the Global Leadership and Organization Behavior Effectiveness (GLOBE, [20]). We took the average cultural values among the countries in the Middle East for the United Arab Emirates, since GLOBE does not provide data for this country.

\section{Data analysis}

\subsection{Correlation analysis}

In line with common practice in meta-analytic studies [47], we first adjusted correlations for measurement error. Next, we transformed the reliability-corrected correlations into Fisher's zcoefficients and weighed them using their inverse variance to give more weight to more accurate measures. We further transformed the z-scores back to obtain mean correlations between the key factors and users' intention for the adoption of wearable technology. Furthermore, we calculated the standard error and confidence interval of the mean effect, and estimated the fail-safe sample size $\left(\mathrm{N}_{\mathrm{fs}}\right)$ using Rosenthal's [46] method to assess the possibility of publication bias or the file drawer problem. Finally, we tested the hypothesis of homogeneity of the population correlations using the $Q$-statistic and the $I^{2}$-statistic [2].

Table 2 presents the results. In support of $\mathrm{H}_{1}-\mathrm{H}_{5}$, the generalized correlations demonstrated that perceived usefulness, perceived ease of use, perceived enjoyment, and perceived self-expressiveness positively influenced consumers' responses to wearable technology adoption, while perceived privacy risk negatively affected consumers' responses to wearable technology adoption. Specifically, for attitude towards wearable technology, perceived enjoyment had the highest effect $(r=.754)$, followed by perceived usefulness $(\mathrm{r}=.694)$, perceived self-expressiveness $(\mathrm{r}$ $=.563)$, perceived ease of use $(\mathrm{r}=.522)$, and perceived privacy risk $(\mathrm{r}=-.273)$. However, the importance ranking changed for behavioral intention to use wearable technology. In particular, perceived usefulness had the highest effect $(r=.737)$, followed by perceived enjoyment $(r=.647)$, perceived ease of use $(r=.502)$, perceived self-expressiveness $(r=.475)$, and perceived privacy risk $(\mathrm{r}=-.292)$. Moreover, we can observe that these factors impact attitude almost as strongly as behavioral intention.

Furthermore, all the relationships that are heterogeneous were indicated by a high value of $\mathrm{I}^{2}$ (greater than 75\%) and Q $(<.001)$ [19], with one exception that the relationship between perceived privacy risk and attitude towards wearable technology adoption had the $\mathrm{I}^{2}$ of $72.36 \%$, close to $75 \%$. These tests imply that it is necessary to conduct moderating analysis. Also, high fail-safe sample sizes $\left(\mathrm{N}_{\mathrm{fs}}\right)$ prove there exists no publication bias in our database.

Table 2. Correlations between different factors and wearable technology adoption

\begin{tabular}{|c|c|c|c|c|c|c|c|c|}
\hline Relationships & $\begin{array}{l}\text { Number of } \\
\text { samples }\end{array}$ & $\begin{array}{l}\text { Number of } \\
\text { effects }\end{array}$ & $\begin{array}{l}\text { Number of } \\
\text { observations }\end{array}$ & Q-value & 12 & $\begin{array}{l}\text { Mean } \\
\text { correlations }\end{array}$ & $95 \% \mathrm{Cl}$ & $\begin{array}{l}\text { Fail- } \\
\text { safe N }\end{array}$ \\
\hline Usefulness - Attitude & 12 & 12 & 5533 & $503.103^{* * *}$ & $97.60 \%$ & .694 & $(.579, .782)$ & 11214 \\
\hline Ease of use - Attitude & 11 & 11 & 5507 & $180.322^{* * *}$ & $95.71 \%$ & .522 & $(.405, .621)$ & 4356 \\
\hline Enjoyment - Attitude & 7 & 7 & 3346 & $135.652^{* * *}$ & $96.88 \%$ & .754 & $(.642, .834)$ & 6134 \\
\hline Self-expressiveness - Attitude & 6 & 6 & 2646 & $44.614^{* * *}$ & $89.20 \%$ & .563 & $(.460, .651)$ & 1790 \\
\hline Privacy risk - Attitude & 2 & 2 & 1426 & $3.618^{* * *}$ & $72.36 \%$ & -.273 & $(-.372,-.168)$ & 64 \\
\hline Usefulness - Behavioral intention & 36 & 39 & 15119 & $1311.223^{* *}$ & ${ }^{*} 96.59 \%$ & .737 & $(.563, .684)$ & 81023 \\
\hline Ease of use - Behavioral intention & 24 & 25 & 9623 & $571.571^{* * *}$ & $96.03 \%$ & .502 & $(.410, .584)$ & 15657 \\
\hline Enjoyment - Behavioral intention & 18 & 19 & 7094 & $449.598^{* * *}$ & $96.42 \%$ & .647 & $(.559, .720)$ & 22621 \\
\hline $\begin{array}{l}\text { Self-expressiveness - Behavioral } \\
\text { intention }\end{array}$ & 7 & 7 & 2874 & $258.903^{* \star *}$ & $95.80 \%$ & .475 & $(.296, .622)$ & 1286 \\
\hline Privacy risk - Behavioral intention & 11 & 11 & 5413 & $327.215^{* * *}$ & $94.37 \%$ & -.292 & $(-.413,-.161)$ & 1688 \\
\hline
\end{tabular}
${ }^{* * *} p<.001$

\subsection{Moderation analysis}

To conduct moderation analysis, we first combined effect sizes for attitude with those for behavioral intention to enlarge the number of effect sizes. Considering that the number of effect sizes is still not huge, we accepted a simple random-effects meta-analytic model that only contains one moderator and a dummy control variable referring to whether the effect size connects attitude or behavioral intention. Following prior meta-analyses [42], we applied this model to test each moderator in turn with the maximum likelihood estimation method.

Table 3 presents the results of the meta-regression models. The findings in the various regression models were used to test H6-H12, as indicated in Table 3. As expected, a positive coefficient was found to be related 
to uncertainty avoidance when testing the influence on the effect size representing the relationship perceived usefulness-adoption. This finding shows that uncertainty avoidance did increase the positive influence of perceived usefulness on adoption (H6). We found a negative coefficient of uncertainty avoidance on the relationship perceived privacy riskadoption. In other words, the negative impact of perceived privacy risk on adoption becomes stronger with the increase in uncertainty avoidance (H7). In support of $\mathrm{H} 8$, it can be seen that future orientation indeed positively influenced the effect of perceived usefulness on adoption. However, contrasting with H9, we did not find any evidence that future orientation would moderate the relationship perceived enjoymentadoption. The hypotheses (H10-H11) related to humane orientation were supported, showing humane orientation could strengthen the positive effect of perceived ease of use on adoption, while weakening the negative effect of perceived privacy risk on adoption. In addition, the relationship between perceived self-expressiveness and adoption was stronger for smartwatches than other types of wearable technologies (H12 was supported).

Table 3. Moderating effects: meta-regression estimates

\begin{tabular}{|c|c|c|c|c|c|c|c|c|c|c|c|c|}
\hline \multicolumn{13}{|c|}{ Independent variables } \\
\hline & \multicolumn{3}{|c|}{$\begin{array}{l}\text { Model } \\
\text { (1) }\end{array}$} & \multicolumn{3}{|c|}{$\begin{array}{l}\text { Model } \\
(2)\end{array}$} & \multicolumn{3}{|c|}{$\begin{array}{l}\text { Model } \\
\text { (3) }\end{array}$} & \multicolumn{3}{|c|}{$\begin{array}{l}\text { Model } \\
\text { (4) }\end{array}$} \\
\hline & Intercept & $\begin{array}{l}\text { Uncertainty } \\
\text { avoidance }\end{array}$ & Attitude & Intercept & $\begin{array}{l}\text { Future } \\
\text { orientation }\end{array}$ & Attitude & Intercept & $\begin{array}{l}\text { Humane } \\
\text { orientation }\end{array}$ & Attitude & Intercept & $\begin{array}{c}\text { Smart } \\
\text { watches }\end{array}$ & Attitude \\
\hline $\begin{array}{l}\text { Usefulness- } \\
\text { adoption }\end{array}$ & $\begin{array}{l}.348 \\
(.312)\end{array}$ & $\begin{array}{l}.123 \\
(.072)^{+}\end{array}$ & $\begin{array}{l}-.151 \\
(.104)\end{array}$ & $\begin{array}{l}-.776 \\
(.742)\end{array}$ & $\begin{array}{c}.399 \\
(.180)^{*}\end{array}$ & $\begin{array}{l}-.082 \\
(.102)\end{array}$ & $\begin{array}{l}.934 \\
(.458)^{*}\end{array}$ & $\begin{array}{l}-.020 \\
(.116)\end{array}$ & $\begin{array}{l}-.116 \\
(.107)\end{array}$ & $\begin{array}{l}.812 \\
(.099)^{* * * *}\end{array}$ & $\begin{array}{l}.104 \\
(.096)\end{array}$ & $\begin{array}{l}-.104 \\
(.105)\end{array}$ \\
\hline $\begin{array}{l}\text { Ease of } \\
\text { use- } \\
\text { adoption }\end{array}$ & $\begin{array}{l}.090 \\
(.320)\end{array}$ & $\begin{array}{l}.123 \\
(.078)\end{array}$ & $\begin{array}{l}-.058 \\
(.098)\end{array}$ & $\begin{array}{l}-.245 \\
(.904)\end{array}$ & $\begin{array}{l}.204 \\
(.222)\end{array}$ & $\begin{array}{l}-.016 \\
(.099)\end{array}$ & $\begin{array}{l}-.559 \\
(.443)\end{array}$ & $\begin{array}{l}.285 \\
(.109)^{* *}\end{array}$ & $\begin{array}{l}-.059 \\
(.092)\end{array}$ & $\begin{array}{l}.507 \\
(.090)^{* * * *}\end{array}$ & $\begin{array}{c}.161 \\
(.095)^{+}\end{array}$ & $\begin{array}{l}-.003 \\
(.097)\end{array}$ \\
\hline $\begin{array}{l}\text { Enjoyment- } \\
\text { adoption }\end{array}$ & $\begin{array}{l}1.163 \\
(.413)^{* *}\end{array}$ & $\begin{array}{l}-.045 \\
(.099)\end{array}$ & $\begin{array}{l}-.199 \\
(.132)\end{array}$ & $\begin{array}{l}-1.375 \\
(1.669)\end{array}$ & $\begin{array}{l}.591 \\
(.418)\end{array}$ & $\begin{array}{l}-.217 \\
(.125)^{+}\end{array}$ & $\begin{array}{l}.469 \\
(.690)\end{array}$ & $\begin{array}{l}.134 \\
(.179)\end{array}$ & $\begin{array}{l}-.240 \\
(.134)^{+}\end{array}$ & $\begin{array}{l}.885 \\
(.135)^{* * *}\end{array}$ & $\begin{array}{l}.136 \\
(.116)\end{array}$ & $\begin{array}{l}-.172 \\
(.131)\end{array}$ \\
\hline $\begin{array}{l}\text { Self- } \\
\text { expressiven } \\
\text { ess- } \\
\text { adoption }\end{array}$ & $\begin{array}{l}.915 \\
(.394)^{*}\end{array}$ & $\begin{array}{l}-.070 \\
(.096)\end{array}$ & $\begin{array}{l}-.117 \\
(.123)\end{array}$ & $\begin{array}{c}.377 \\
(1.152)\end{array}$ & $\begin{array}{l}.063 \\
(.281)\end{array}$ & $\begin{array}{l}-.118 \\
(.125)\end{array}$ & $\begin{array}{l}-.265 \\
(1.054)\end{array}$ & $\begin{array}{l}.241 \\
(.281)\end{array}$ & $\begin{array}{l}-.133 \\
(.123)\end{array}$ & $\begin{array}{l}.525 \\
(.097)^{* * * *}\end{array}$ & $\begin{array}{l}.218 \\
(.109)^{*}\end{array}$ & $\begin{array}{l}-.104 \\
(.109)\end{array}$ \\
\hline $\begin{array}{l}\text { Privacy } \\
\text { risk- } \\
\text { adoption }\end{array}$ & $\begin{array}{l}.567 \\
(.459)\end{array}$ & $\begin{array}{c}-.182 \\
(.095)^{+}\end{array}$ & $\begin{array}{l}-.024 \\
(.135)\end{array}$ & $\begin{array}{c}.046 \\
(1.135)\end{array}$ & $\begin{array}{l}-.079 \\
(.271)\end{array}$ & $\begin{array}{l}-.029 \\
(.157)\end{array}$ & $\begin{array}{l}-1.293 \\
(.362)^{* * *}\end{array}$ & $\begin{array}{c}.258 \\
(.088)^{* *}\end{array}$ & $\begin{array}{l}-.025 \\
(.119)\end{array}$ & $\begin{array}{l}-.280 \\
(.141)^{*}\end{array}$ & 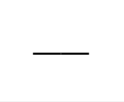 & $\begin{array}{l}-.021 \\
(.155)\end{array}$ \\
\hline Hypotheses & $\begin{array}{l}\text { Uncert } \\
\text { perceive } \\
\text { perceive }\end{array}$ & $\begin{array}{l}\text { ainty avoida } \\
\text { d usefulnes } \\
\text { d privacy ri }\end{array}$ & $\begin{array}{l}\text { ece for } \\
\left(\mathrm{H}_{6}:+\right) \\
\mathrm{k}\left(\mathrm{H}_{7}:-\right)\end{array}$ & $\begin{array}{l}\text { Futur } \\
\text { perceivec } \\
\text { perceive }\end{array}$ & $\begin{array}{l}\text { re orientatio } \\
\text { d usefulnes } \\
\text { ed enjoymer }\end{array}$ & $\begin{array}{l}\text { on for } \\
\text { s }\left(\mathrm{H}_{8}:+\right) \text {; } \\
\text { nt }\left(\mathrm{H}_{9}:-\right)\end{array}$ & $\begin{array}{r}\text { Huma } \\
\text { perceiv } € \\
+ \text { ); percei }\end{array}$ & $\begin{array}{l}\text { ane orientati } \\
\text { ed ease of u } \\
\text { ived privacy } \\
+ \text { ) }\end{array}$ & $\begin{array}{l}\text { ion for } \\
\text { use }\left(\mathrm{H}_{10} \text { : }\right. \\
\text { risk }\left(\mathrm{H}_{11} \text { : }\right.\end{array}$ & $\begin{array}{r}p \\
\text { expr } \\
\end{array}$ & $\begin{array}{l}\text { nartwatch } \\
\text { erceived } \\
\text { ressivenes } \\
+ \text { ) }\end{array}$ & $\begin{array}{l}\text { es for } \\
\text { self- } \\
\text { ss }\left(H_{12} \text { : }\right.\end{array}$ \\
\hline Supported? & & Yes/Yes & & & Yes/No & & & Yes/Yes & & & Yes & \\
\hline
\end{tabular}

Note: The perceived privacy risk-adoption model does not have effect sizes from smartwatches. Standard errors are in the parentheses.

${ }^{+} p<.1 ;{ }^{*} p<.05 ;{ }^{* *} p<.01 ;{ }^{* * *} p<.001$

\section{Discussions}

\subsection{Research contribution}

The meta-analysis review study makes several contribution to the literature and also has various implications for theory and future research. First, the current state of research only provides fragmented and relatively divergent findings regarding the driving factors of wearable technology adoption. One of the main contribution is that this study integrates the existing findings and proposes a comprehensive framework for the relationships between five main determinants and wearable technology adoption. More importantly, all the proposed factors were proven as important predictors for wearable adoption, including perceived usefulness, perceived ease of use, perceived enjoyment, perceived self-expressiveness, and perceived privacy risk. These variables can be regarded as the essential determinants of the adoption of wearable products and devices and should be taken into account in further attempts to construct and test explanatory models.

Second, the generalized correlations also provide an in-depth explanation and understanding of the importance of different determinants. We found that both perceived usefulness and perceived enjoyment are the most important drivers of wearable technology adoption. This finding contributes to the debate about 
whether wearable technology is an IT product or a fashion product [11]. The comparison between technology benefits (perceived usefulness, perceived ease of use, perceived enjoyment, and perceived selfexpressiveness) and privacy risk revealed that technology benefits weigh heavier to consumers than privacy risk. This observation provides an important explanation to the debate on the privacy paradox that while the privacy of personal data is an important issue for information technology users, most users seldom make an effort to protect their own data [52].

Third, we found the moderating roles of crosscultural factors and cross-wearable types in the relationships between different factors and adoption, which makes a considerable contribution to the wearable-related research field. For example, the predicted difference in effect size capturing the impact of perceived usefulness between the Netherlands (as the most future-oriented country in the analysis), and the United Arab Emirates, as the least future-oriented one, is up to .403. The cross-cultural findings contribute to the debate about the robustness of research conclusions drawn in different cultures [3]. Therefore, it is necessary to add cultural contingency factors into the model of wearable technology adoption. In addition, the findings also reveal that wearable technology types can be considered as significant moderating variables which enrich the research on the adoption of wearables.

\subsection{Practical implications}

This study provides several implications to business practitioners and wearables designers. First, the market of smart wearable devices is still at the initial stage. Practitioners have relatively less knowledge about consumers' attitude towards smart wearable devices than other mature information technologies. The proposed framework and the generalization analysis offer firms an overview of what kinds of, how and under which conditions, different factors are important to wearable technology adoption. Based on the results, business practitioners should make efforts to improve perceived usefulness, perceived ease of use, perceived enjoyment, and perceived self-expressiveness, and decrease perceived privacy risk.

Second, according to the analysis of the relative importance of factors to wearable adoption, we can find that both perceived usefulness and perceived enjoyment are the most important drivers of the adoption of wearables. These findings suggest that a smart wearable product is not only an IT product, but also a hedonic fashion product. If designers only focus on technical innovation, users might not have a high willingness to adopt a certain wearable product. Furthermore, given the magnitude of perceived privacy risk's negative effect is far smaller than that of technology benefits, wearable developers may require more of consumers' data to advance product performance and offer more personalized service.

Third, moderation analysis suggests that wearable firms need to adopt different business strategies to develop or promote wearable products in different cultures for various types of wearable technology. In particular, for a high-uncertainty avoidance culture, firms should improve and highlight perceived usefulness, and reduce consumers' privacy concerns, such as explicitly showing how to collect and use personal data. For the future-oriented culture, firms also should put perceived usefulness into consideration. Regarding the high-humane culture, firms need to invest in perceived ease of use to enhance consumers' well-being. Meanwhile, consumers are more willing to trust firms with their personal data. Also, firms should realize that consumers expect higher symbolic benefits, such as self-expressiveness, for smartwatches than other types of wearable products.

\section{Conclusions}

This study aims at determining the key factors which influence wearable technology adoption through a meta-analytic review of prior research. We proposed an integrated and comprehensive framework of the relationships between different factors and wearable technology adoption. In addition, we explain the crosscultural and cross-wearable technology type differences via moderation analysis. In obtaining these findings, we enhance the understanding of wearable technology adoption. However, there are still other technological and non-technological factors that influence wearable adoption.

Further, in this study, we investigated the boundary conditions for the relationships between different determinants and wearable adoption from the perspective of culture (e.g., uncertainty avoidance, future orientation, and humane orientation), involving in total 11 countries. It can be seen that the analysis was mostly still limited in China, US, and Korea. Thus, with the development of the research related to wearable adoption in other countries, we encourage future studies to conduct a more in-depth analysis and robustness check on the cultural-related factors.

\section{Acknowledgments}

This work was supported by the National Natural Science Foundation of China under Grant No. 
71972175; Academy of Finland SRC CULT Programme under Grant No. 327241 (Digiconsumers) and Academy of Finland Flagship Programme under Grant No. 337653 (Forest-Human-Machine Interplay (UNITE).

\section{References}

[1] A. T. Abraham, and R. W. Hamilton, "When does partitioned pricing lead to more favorable consumer preferences?: Meta-analytic evidence", Journal of Marketing Research, 55(5), 2018, pp. 686-703.

[2] M. Borenstein, L. V. Hedges, J. P. Higgins, and H. R. Rothstein, Introduction to Meta-Analysis. John Wiley \& Sons, 2009.

[3] S. M. Burgess, and J. B. E. Steenkamp, "Marketing renaissance: How research in emerging markets advances marketing science and practice", International Journal of Research in Marketing, 23(4), 2006, pp. 337-356.

[4] O. O. Buruk, M. Salminen, N. Xi, T. Nummenmaa, and J. Hamari, "Towards the next generation of gaming wearables", In Proceedings of the 2021 CHI Conference on Human Factors in Computing Systems, 2021, Article no. 44.

[5] H. S. Chang, S. C. Lee, and Y. G. Ji, "Wearable device adoption model with TAM and TTF", International Journal of Mobile Communications, 14(5), 2016, pp. 518-537.

[6] W. Chang, and S. A. Taylor, "The effectiveness of customer participation in new product development: A metaanalysis", Journal of Marketing, 80(1), 2016, pp. 47-64.

[7] M. L. Cheung, K. Y. Chau, M. H. S. Lam, G. Tse, K. Y. Ho, S. W. Flint, ..., and K. Y. Lee, "Examining consumers' adoption of wearable healthcare technology: The role of health attributes", International Journal of Environmental Research and Public Health, 16(13), 2019, Article no. 2257.

[8] R. Chitturi, R. Raghunathan, and V. Mahajan, "Form versus function: How the intensities of specific emotions evoked in functional versus hedonic trade-offs mediate product preferences", Journal of Marketing Research, 44(4), 2007, pp. 702-714.

[9] R. Chitturi, R. Raghunathan, and V. Mahajan, "Delight by design: The role of hedonic versus utilitarian benefits", Journal of Marketing, 72(3), 2008, pp. 48-63.

[10] B. Choi, S. Hwang, and S. Lee, "What drives construction workers' acceptance of wearable technologies in the workplace?: Indoor localization and wearable health devices for occupational safety and health", Automation in Construction, 84, 2017, pp. 31-41.

[11] J. Choi, and S. Kim, "Is the smartwatch an IT product or a fashion product? A study on factors affecting the intention to use smartwatches", Computers in Human Behavior, 63, 2016, pp.777-786.

[12] S. H. W. Chuah, P. A. Rauschnabel, N. Krey, B. Nguyen, T. Ramayah, and S. Lade, "Wearable technologies: The role of usefulness and visibility in smartwatch adoption", Computers in Human Behavior, 65, 2016, 276-284.

[13] F. D. Davis, "Perceived usefulness, perceived ease of use, and user acceptance of information technology", MIS Quarterly, 13, 1989, pp. 319-340.

[14] S. Diehl, R. Terlutter, and B. Mueller, "Doing good matters to consumers: the effectiveness of humane-oriented
CSR appeals in cross-cultural standardized advertising campaigns", International Journal of Advertising, 35(4), 2016, pp. 730-757.

[15] Y. Gao, H. Li, and Y. Luo, "An empirical study of wearable technology acceptance in healthcare", Industrial Management \& Data Systems, 115(9), 2015, pp. 1704-1723.

[16] A. M. Harmon, A Quantitative Predictive Study of US Fitbit Owners' Intentions to Use Activity Trackers, Doctoral dissertation, Capella University, 2019.

[17] M. Herz, and P. A. Rauschnabel, "Understanding the diffusion of virtual reality glasses: The role of media, fashion and technology", Technological Forecasting and Social Change, 138, 2019, pp. 228-242.

[18] E. T. Higgins, "Beyond pleasure and pain", American Psychologist, 52(12), 1997, pp. 1280-1300.

[19] J. P. Higgins, and S. G. Thompson, "Quantifying heterogeneity in a meta-analysis", Statistics in Medicine, 21(11), 2002, pp. 1539-1558.

[20] R. J. House, P. J. Hanges, M. Javidan, P. W. Dorfman, and V. Gupta, Culture, Leadership, and Organizations: The Globe Study Of 62 Societies. Sage Publications, 2004

[21] K. L. Hsiao, "What drives smartwatch adoption intention? Comparing Apple and non-Apple watches", Library Hi Tech, 35(1), 2017, pp. 186-206.

[22] K. L. Hsiao, and C. C. Chen, "What drives smartwatch purchase intention? Perspectives from hardware, software, design, and value", Telematics and Informatics, 35(1), 2018, pp. 103-113.

[23] R. P. Jindal, K. R. Sarangee, R. Echambadi, and S. Lee, "Designed to succeed: Dimensions of product design and their impact on market share", Journal of Marketing, 80(4), 2016, pp. 72-89.

[24] J. Kim, E. Park, "Beyond coolness: Predicting the technology adoption of interactive wearable devices" Journal of Retailing and Consumer Services, 49, 2019, pp. 114-119.

[25] K. J. Kim, "Round or square? How screen shape affects utilitarian and hedonic motivations for smartwatch adoption", Cyberpsychology, Behavior, and Social Networking, 19(12), 2016, pp. 733-739.

[26] K. J. Kim, and D. H. Shin, "An acceptance model for smart watches: implications for the adoption of future wearable technology", Internet Research, 25(4), 2015, pp. 527-541.

[27] T. Kim, and W. Chiu, "Consumer acceptance of sports wearable technology: the role of technology readiness", International Journal of Sports Marketing and Sponsorship, 20(1), 2019, pp. 109-126.

[28] A. K. Kranthi, and K. A. Ahmed, "Determinants of smartwatch adoption among IT professionals-an extended UTAUT2 model for smartwatch enterprise", International Journal of Enterprise Network Management, 9(3-4), 2018, pp. 294-316.

[29] S. T. Kwee-Meier, J. E. Bützler, and C. Schlick, "Development and validation of a technology acceptance model for safety-enhancing, wearable locating systems", Behaviour \& Information Technology, 35(5), 2016, pp. 394409.

[30] C. J. Lennings, and A. M. Burns, "Time perspective: Temporal extension, time estimation, and impulsivity", The Journal of Psychology, 132(4), 1998, pp. 367-380. 
[31] H. Li, J. Wu, Y. Gao, and Y. Shi, "Examining individuals' adoption of healthcare wearable devices: An empirical study from privacy calculus perspective", International Journal of Medical Informatics, 88, 2016, pp. 817.

[32] J. Li, Q. Ma, A. H. Chan, and S. S. Man, "Health monitoring through wearable technologies for older adults: Smart wearables acceptance model", Applied Ergonomics, 75, 2019, pp. 162-169.

[33] A. Lunney, N. R. Cunningham, and M. S. Eastin, "Wearable fitness technology: A structural investigation into acceptance and perceived fitness outcomes", Computers in Human Behavior, 65, 2016, pp. 114-120.

[34] A. Marakhimov, and J. Joo, "Consumer adaptation and infusion of wearable devices for healthcare", Computers in Human Behavior, 76, 2017, pp. 135-148.

[35] C. Marino, G. Gini, A. Vieno, and M. M. Spada, "A comprehensive meta-analysis on problematic Facebook use", Computers in Human Behavior, 83, 2018, pp. 262-277.

[36] K. R. Morrison, and C. S. Johnson, "When what you have is who you are: Self-uncertainty leads individualists to see themselves in their possessions", Personality and Social Psychology Bulletin, 37(5), 2011, pp. 639-651.

[37] B. Nascimento, T. Oliveira, and C. Tam, "Wearable technology: What explains continuance intention in smartwatches?", Journal of Retailing and Consumer Services, 43, 2018, pp. 157-169.

[38] E. C. Nelson, T. Verhagen, M. Vollenbroek-Hutten, and M. L. Noordzij, "Is wearable technology becoming part of us? Developing and validating a measurement scale for wearable technology embodiment", JMIR mHealth and uHealth, 7(8), 2019, Article no. e12771

[39] T. J. Noseworthy, and R. Trudel, "Looks interesting, but what does it do? Evaluation of incongruent product form depends on positioning", Journal of Marketing Research, 48(6), 2011, pp. 1008-1019.

[40] A. Papa, M. Mital, P. Pisano, and M. D. Giudice, "Ehealth and wellbeing monitoring using smart healthcare devices: An empirical investigation", Technological Forecasting and Social Change, 153, 2018, Article no. 119226.

[41] E. Park, K. J. Kim, and S. J. Kwon, "Understanding the emergence of wearable devices as next-generation tools for health communication", Information Technology \& People, 29(4), 2016, pp. 717-732.

[42] N. Purnawirawan, M. Eisend, P. De Pelsmacker, and N. Dens, "A meta-analytic investigation of the role of valence in online reviews", Journal of Interactive Marketing, 31, 2015, pp. 17-27.

[43] P. A. Rauschnabel, "Virtually enhancing the real world with holograms: An exploration of expected gratifications of using augmented reality smart glasses", Psychology \& Marketing, 35(8), 2018, pp. 557-572.

[44] P. A. Rauschnabel, and Y. K. Ro, "Augmented reality smart glasses: An investigation of technology acceptance drivers", International Journal of Technology Marketing, 11(2), 2016, pp. 123-148.

[45] P. A. Rauschnabel, A. Brem, and B. S. Ivens, "Who will buy smart glasses? Empirical results of two pre-marketentry studies on the role of personality in individual awareness and intended adoption of Google Glass wearables", Computers in Human Behavior, 49, 2015, pp. 635-647.

[46] R. Rosenthal, "The file drawer problem and tolerance for null results", Psychological Bulletin, 86(3), 1979, pp. 638-641.

[47] G. Rubera, and A. H. Kirca, "Firm innovativeness and its performance outcomes: A meta-analytic review and theoretical integration", Journal of Marketing, 76(3), 2012, pp. 130-147.

[48] Z. Şehbenderoğlu, "Predicting the Adoption of Wearable Health Tracking Devices: An Application of Diffusion of Innovation Theory”, 2019. http://dx.doi.org/10.2139/ssrn.3427919

[49] K. Sergueeva, N. Shaw, and S. H. M. Lee, "Understanding the barriers and factors associated with consumer adoption of wearable technology devices in managing personal health", Canadian Journal of Administrative Sciences, 37, 2020, 45-60.

[50] C. W. Shen, J. T. Ho, P. T. M. Ly, and T. C. Kuo, "Behavioural intentions of using virtual reality in learning: perspectives of acceptance of information technology and learning style" Virtual Reality, 23(3), 2019, pp. 313-324.

[51] B. Sivathanu, "Adoption of internet of things (IOT) based wearables for healthcare of older adults-a behavioural reasoning theory (BRT) approach", Journal of Enabling Technologies, 12(4), 2018, pp. 169-185.

[52] H. J. Smith, T. Dinev, and H. Xu, "Information privacy research: an interdisciplinary review", MIS Quarterly, 35(4), 2011, pp. 989-1016.

[53] M. R. Solomon, and B. Buchanan, "A role-theoretic approach to product symbolism: Mapping a consumption constellation”, Journal of Business Research, 22(2), 1991, pp. 95-109.

[54] J. B. E. Steenkamp, F. Ter Hofstede, and M. Wedel, "A cross-national investigation into the individual and national cultural antecedents of consumer innovativeness", Journal of Marketing, 63(2), 1999, pp. 55-69.

[55] B. ŠUmak, M. HeričKo, and M. PušNik, "A metaanalysis of e-learning technology acceptance: The role of user types and e-learning technology types", Computers in Human Behavior, 27(6), 2011, pp. 2067-2077.

[56] M. S. Talukder, R. Chiong, Y. Bao, and B. Hayat Malik, "Acceptance and use predictors of fitness wearable technology and intention to recommend: An empirical study", Industrial Management \& Data Systems, 119(1), 2019, pp. $170-188$.

[57] M. S. Talukder, G. Sorwar, Y. Bao, J. U. Ahmed, and M. A. S. Palash, "Predicting antecedents of wearable healthcare technology acceptance by elderly: A combined SEM-Neural Network approach", Technological Forecasting and Social Change, 150, 2020, Article no. 119793.

[58] A. Tarabasz, and G. Poddar, "Factors influencing adoption of wearable devices in Dubai", Journal of Economics \& Management, 36, 2019, pp. 123-143.

[59] S. Tifferet, "Gender differences in privacy tendencies on social network sites: a meta-analysis", Computers in Human Behavior, 93, 2019, pp. 1-12.

[60] G. Turhan, "An assessment towards the acceptance of wearable technology to consumers in Turkey: the application to smart bra and t-shirt products", Journal of the Textile Institute, 104(4), 2013, pp. 375-395. 
[61] V. Venkatesh, J. Y. Thong, and X. Xu, "Consumer acceptance and use of information technology: extending the unified theory of acceptance and use of technology", MIS Quarterly, 36(1), 2012, pp. 157-178.

[62] M. Weng, The acceptance of wearable devices for personal healthcare in China, 2016, Master's thesis, University of Oulu.

[63] R. B. Wiegard, and M. H Breitner, "Smart services in healthcare: A risk-benefit-analysis of pay-as-you-live services from customer perspective in Germany", Electronic Markets, 29(1), 2019, pp. 107-123.

[64] B. E. Winston, and B. Ryan, "Servant leadership as a humane orientation: Using the GLOBE study construct of humane orientation to show that servant leadership is more global than western", International Journal of Leadership Studies, 3(2), 2008, pp. 212-222.

[65] L. H. Wu, L. C. Wu, and S. C. Chang, "Exploring consumers' intention to accept smartwatch", Computers in Human Behavior, 64, 2016, pp. 383-392.
[66] H. Yang, J. Yu, H. Zo, and M. Choi, "User acceptance of wearable devices: An extended perspective of perceived value" Telematics and Informatics, 33(2), 2016, pp. 256-269. [67] H. Yildirim, and A. M. Ali-Eldin, "A model for predicting user intention to use wearable IoT devices at the workplace", Journal of King Saud University-Computer and Information Sciences, 31(4), 2019, pp. 497-505.

[68] C. Yoon, "The effects of national culture values on consumer acceptance of e-commerce: Online shoppers in China”, Information \& Management, 46(5), 2009, pp. 294301.

[69] M. Zhang, M. Luo, R. Nie, and Y. Zhang, "Technical attributes, health attribute, consumer attributes and their roles in adoption intention of healthcare wearable technology", International Journal of Medical Informatics, 108, 2017, pp. 97-109.

[70] P. G. Zimbardo, and J. N. Boyd, "Putting time in perspective: A valid, reliable individual-differences metric". In Time perspective theory; review, research and application, Springer, Cham, 17-55. 